\title{
Heuristic assessment of bridge scour sensitivity using differential evolution: case study for linking floodplain encroachment and bridge scour
}

Lucas J. Howard ${ }^{1 *}$, lan A. Anderson ${ }^{1}$, Kristen L. Underwood ${ }^{1}$, Mandar M. Dewoolkar ${ }^{1}$, Larry M. Deschaine ${ }^{2}$ and Donna M. Rizzo ${ }^{1}$

\begin{abstract}
Background: Stakeholders are often required to make judgments and decisions about the tradeoffs between multiple competing objectives inherent in any engineering design. Design optimization can provide decision support for such situations, but often prescribes that only a single design solution be selected for a given set of preferences. The purpose of this study is to frame an objective function for assessing how the sensitivity of one objective relative to another varies in space and to demonstrate the method using a real site, with spatially-dependent floodplain access and bridge scour as the objective tradeoffs. Bridge scour is a widespread and expensive infrastructure problem, and the proposed methodology provides the ability to assess how the sensitivity of bridge scour to floodplain access varies at different locations in a river reach.

Results: The site chosen for demonstration purposes was the Lewis Creek in the vicinity of the Quinlan Covered Bridge in Charlotte, VT. Differential evolution (DE) was wrapped around an existing HEC-RAS model. The decision variables corresponded to floodplain access at locations up and downstream of the bridge; the objective function was constructed so that optimal solutions may be interpreted as relative salience of floodplain access to bridge scour. Multiple weightings of the objectives were used to verify that the rank-order of locations was robust. The optimal DE solutions for all weightings resulted in the same sensitivity ranking of locations, providing evidence that the analysis is not dependent on a particular choice of stakeholder objective weightings.
\end{abstract}

Conclusions: For systems with spatially dependent variables that impact a constraint or objective of interest to stakeholders, a tool for identifying locations where that variable has a particularly strong or weak impact (e.g. where floodplain access is more or less important for bridge scour) has obvious advantages. This study demonstrates a method for conducting such a sensitivity analysis using a numerical optimization scheme. On the real test site, the sensitivity ranking was consistent across multiple stakeholder weightings, providing evidence that the technique is robust, and one that can be used at multiple stages of design. This work demonstrates the utility of a novel interpretation of optimization results in which locations are ranked according to the relative sensitivity of competing objectives. Keywords: Sensitivity, Optimization, Differential evolution, Decision support, Bridge scour, Floodplain access, HECRAS

\footnotetext{
*Correspondence: lucas.howard@uvm.edu

${ }^{1}$ Civil and Environmental Engineering, University of Vermont, 33

Colchester Avenue, Burlington, VT 05405, USA

Full list of author information is available at the end of the article
} 


\section{Background}

\section{Optimization and sensitivity}

The use of numerical optimization techniques to address real-world environmental and engineering problems, and provide decision support to stakeholders is a common strategy (Rios and Sahinidis 2012). Optimization has been coupled with process-based models of varying complexity to minimize the cost of groundwater remediation or monitoring (Deschaine et al. 2013), to design the shape of a radio antenna for satellites (Hornby et al. 2011), to optimize the control of hydroelectric power plants, and for many other applications (Bartholomew-Biggs et al. 2002; Jeongwoo and Papalambros 2010; Marsden et al. 2004; Mugunthan et al. 2005; Shlomi et al. 2010).

These applications all represent "design optimization problems in which multiple objectives from various stakeholders must be translated into a single objective function (also know as cost or fitness functions) that can be reduced to a scalar value (i.e. cost or fitness) that "adequately" represents the design performance. Stakeholder constraints, preferences, and objectives are encoded in this cost function. In cases with multiple competing objectives, there is no single optimal solution (Jeongwoo and Papalambros 2010). As a result, a number of numerical optimization methods found favor, generically referred to as evolutionary computation (e.g. genetic algorithms, evolutionary algorithms, simulated annealing, and differential evolution). These techniques, inspired by the concepts of natural selection in biological evolution, are able to effectively explore the tradeoffs between competing objectives resulting in, sets of nondominated solutions (Fowler et al. 2015; Xu and Lu 2011) where the design performance in one objective cannot be improved without decreasing its performance in other objectives. Since multiple stakeholders place varying importance on the different objectives and prioritization of constraints (Fowler et al. 2015), there are tradeoffs between the objectives (Fowler et al. 2015; Kurek and Ostfeld 2013) with, for example, increases in contaminant cleanup time being weighed against monetary cost. In such cases, the two or more objectives can be combined into a total, scalar, cost or fitness function to create a single-objective problem (Kurek and Ostfeld 2013). The set of design variables that optimize (i.e. minimize or maximize) this function then corresponds to the optimal design solution.

Sensitivity analysis can also be performed subsequent to, or concurrently with, optimization (Harsha Choday and Roy 2013) in engineering applications (Liou et al. 2013; Mesfin and Shuhaimi 2010). These analyses typically quantify the sensitivity of the objective function to changes in design variables (Guerra-Gómez et al. 2013), near the optimal solution or otherwise (Liou et al. 2013), providing information about the marginal impact of changes in the design-potentially valuable information for designers and other stakeholders.

In this work, we use optimization as a tool to assess sensitivity rather than to find an optimal design. The goal is to wrap optimization around a process-based fluvial model to provide insight into the system behavior and visualize the spatial relationship between variables and competing objectives. More specifically, in cases where an objective is comprised of two or more variables that are functions of space, the proposed method ranks locations according to the sensitivity of the objective to that variable. It does so, not by assessing sensitivity near an optimal solution, but instead by interpreting "optimal" results as indicative of relative-not absolute-sensitivity. Thus, the goal is to ordinally rank locations to provide decision support information.

Such an approach has significant advantages. It limits the need to explicitly weight competing objectives, since it does not prescribe a set of "best" designs, but indicates where, spatially or temporally, a particular variable is more or less important to a given objective. The approach suggested here may be used in the more preliminary stages of planning to provide information about system behavior and guide design criteria development.

In this work, the proposed method is applied to a real hydrologic system-a $1025 \mathrm{~m}$ stretch of a river and a fixed bridge location. Using floodplain access (a spatiallydependent quantity) and bridge scour (the objective), we wrap an evolutionary algorithm around a widely used process-based fluvial model to rank locations up and downstream of the bridge according to the impact of floodplain access or encroachment on predicted scour at the bridge's abutments. These results are relative, and the method may be generically applied to this kind of system to aid in the optimal placement of new bridges or to direct the efficient removal of floodplain encroachments to mitigate bridge scour risk.

\section{Bridge scour and floodplain access}

Bridge scour is the removal of streambed soil and sediments from the supports of bridge foundations caused by water-induced erosion. Scour is the most common cause of bridge failures in the United States (Katell and Eriksson 1998; Arneson et al. 2012) and other parts of the world. For example, Melville and Coleman (1973) report 31 case studies of scour damage to bridges in New Zealand. In another study, Wardhana and Hadipriono (2003) analyzed over 500 cases of bridge failures in the United States from 1989 to 2000 and found that nearly $50 \%$ of the failures related flood and scour. The HEC-18 document mentions numerous examples of scour related bridge damage and failure. It also reports that flooding in 
1993 caused the failure of 23 bridges in the upper Mississippi basin at an approximate cost of $\$ 13$ million and in the following year, flooding was responsible for $\$ 130$ million of damage to bridges in Georgia including about 180 bridges in need of replacement (Arneson et al. 2012). More recently, Tropical Storm Irene damaged over 300 bridges in Vermont and $61 \%$ of the affected bridges had scour-related damage (Anderson et al. 2014). The average cost of repairing the scour damage from Tropical Storm Irene has been estimated at about $\$ 240,000$ (or about $\$ 310$ per square meter of deck area) (Anderson et al. 2014). Arneson et al. (2012) estimated the cost of a total bridge failure to be $2-10$ times the cost of the bridge itself. The available case studies have indicated that repairing a scour-damaged bridge after-the-fact is onerously expensive, and remediating scour-critical bridges may be more economical in the long run.

The bridge repair and replacement costs mentioned above include only the direct costs of repair. If a bridge must be closed for repairs or fails altogether, there are cascading secondary costs due to lost time and decreased productivity of travelers, not to mention the very real risk of injuries and fatalities if scour damage results in unexpected and sudden bridge failure. When these secondary costs are considered, the total average cost of a single bridge failure is estimated at $\$ 13$ million (Briaud et al. 2014) -and over 23,000 bridges were classified as critical in 2011 in the United States, representing nearly $5 \%$ of all bridges (Arneson et al. 2012). Given that scour is the leading cause of bridge failure and that hundreds of bridges are expected to experience flooding in excess of the 100-year flood annually (Arneson et al. 2012), the scale of this infrastructure management problem is clear.

Floodplain constriction is a key factor in scour damage risk (Anderson et al. 2014) as floodplains are vital to the attenuation of flood waves during storm events (Luke et al. 2015). Thus from the perspective of bridge scour, increases in channel flow, velocity and water surface elevation can lead to increased scour potential. The linkage between bridge scour and floodplain access is complicated by the fact that roads and bridges are often placed near or across rivers and streams cutting them off from their natural floodplains. Lack of floodplain access often increases stream velocities, worsening in-stream incision and bank erosion, which in turn increases vulnerability to scour. Developing smart remediation strategies that reduce stream velocities and bridge scour during large storm events and help ameliorate the tradeoffs between human infrastructure needs and protection of the natural environment is critical for long-term sustainability. Mitigating scour risk by restoring floodplain access (i.e. regions adjacent to the stream channel which may become inundated during high-flow events) away from the bridge would help attenuate flood waves and result in smaller peak stage and discharge during storm events, which has obvious benefits that extend beyond bridge scour mitigation. Increased floodplain access may be beneficial in two ways: by decreasing backwaters, increases in water elevation upstream of constrictions, and decreasing peak flow velocities created downstream of constrictions.

The importance of floodplain constriction by bridge structures is fairly well understood and various works have investigated these effects or calculated bridge scour at abutments in the floodplain (Kouchakzadeh and Townsend 1997). Additionally, there have been studies which describe the use of fuse plugs for flood mitigation (Jaffe and Sanders 2001; Pugh 1985; Schmocker et al. 2013). Fuse plugs allow access to floodplains during high flow events, and work on the assumption that increased floodplain access will result in non-local attenuation, i.e. attenuation of the flood wave away from the fuse plug. However, to the best of our knowledge, prior research investigating the impacts of floodplain constriction (other than bridge structure constriction) on scour has not been published. A tool that can assess the relative sensitivity of bridge scour to floodplain access at different locations in a river reach has obvious benefits for this scenario.

In addition to mitigating scour at existing bridges, consideration of floodplain access is important when planning the location of new bridges. An understanding of the relative sensitivity of floodplain access at different locations has the potential to be very powerful. As previously mentioned, a bridge itself constitutes floodplain encroachment and becomes essentially part of the hydraulic and hydrologic river system. Whether the engineering problem at hand is to mitigate risk for a bridge at a fixed location, optimal placement of a new bridge to minimize scour risk within design constraints, or best placing an unavoidable encroachment when flexibility exists, understanding the sensitivity of scour to floodplain access at different locations both up and downstream of the bridge (existing or proposed) is key.

\section{Differential evolution}

Evolutionary computation (EC) is a class of numerical optimization techniques using biologically analogous concepts (Fig. 1). EC methods use "populations" of candidate solutions that are recombined, mutated and reproduce using a form of trial and error that attempts to optimally maximize (or minimize) a global fitness (or cost) function.

Differential evolution (DE) is a stochastic, populationbased EC algorithm (Rios and Sahinidis 2012) designed for global optimization of real-valued functions with 


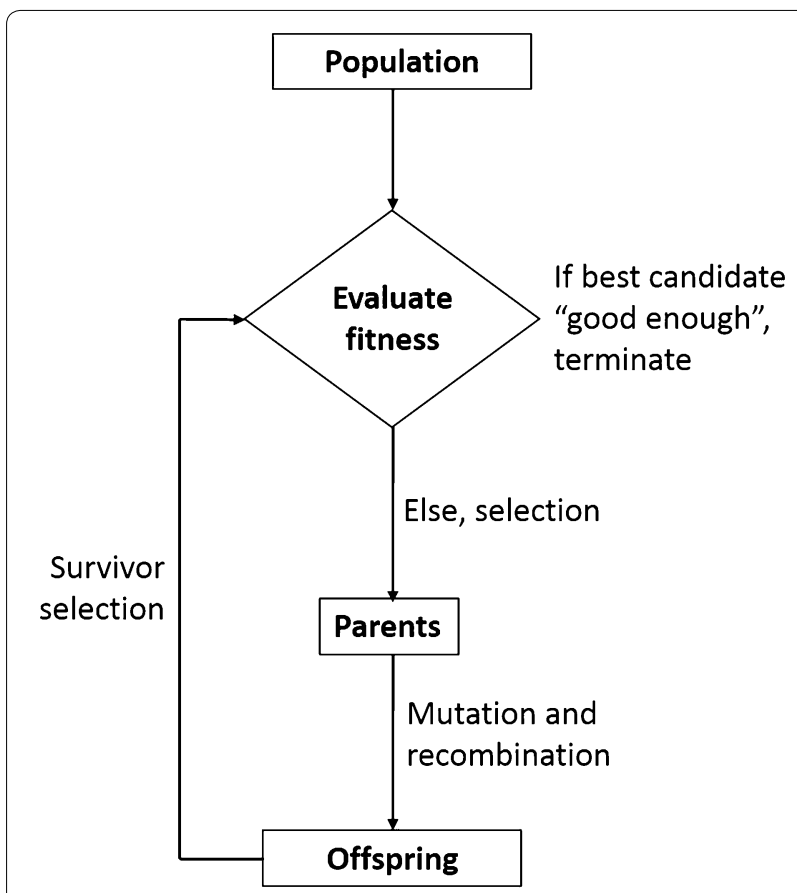

Fig. 1 A flow chart of a generic evolutionary computation algorithm, in which a population of candidate solutions is initialized, a set of offspring candidates produced, and a new set of potential solutions is chosen for the next generation based on fitness

multiple variables (Storn and Price 1997). These design variables specify a design solution that is evaluated by combining one or more objectives into a scalar-valued objective function. This function can then be optimized. It is often referred to as a cost function when the design problem is framed as a minimization problem or a fitness function when framed for maximization in the context of evolutionary algorithms. For this work, minimization was chosen and the function to be optimized will be referred to throughout as the cost function. Generally, constraints can be treated either as additional objectives to be minimized with penalty terms added to force convergence to feasible solutions (Bartholomew-Biggs et al. 2002). They can also be enforced explicitly, with the search limited to feasible regions of the search space (Storn and Price 1997).

$\mathrm{DE}$ is an evolutionary algorithm, which solves real parameter and real value problems (Storn and Price 1997). The DE algorithm begins with initialization of the population, selected from a uniform distribution that covers the entire parameter space. Individual candidate solutions are modified using biologically-analogous mutation and crossover operations to explore the search space. These operations are controlled by two parameters, the crossover fraction and the mutation factor. Details on the mechanisms of the algorithm are described by Storn and Price (1997). In a general sense, the algorithm creates a set of potential solutions referred to as the population. These candidates are then perturbed, and their fitness (cost) evaluated to determine how suitable they are. The next generation is then chosen from any combination of the original population and the perturbed "offspring" based on their fitness scores. DE has been shown to outperform many other evolutionary algorithms on standard benchmark and real-world problems (Vesterstrom and Thomsen 2004).

DE has been successfully used on a cost function containing an implicit weighting of multiple objectives, resulting in a significantly improved design (Hornby et al. 2011). These kinds of tradeoffs encoded in a cost or fitness function have been discussed and utilized in applications including satellite antenna design (Hornby et al. 2011), optimizing the performance and operation of hydroelectric power plants ( $\mathrm{Li}$ et al. 2015), and optimal management of groundwater remediation and management (Deschaine et al. 2013; Rizzo and Dougherty 1996). Sensitivity of the cost function to changes in the design variables near the optimum (Dougherty and Marryott 1991) is one way to evaluate relative sensitivity. However, interpretation of the optimal values of the decision variables themselves as relative sensitivity has not been proposed to the best of our knowledge.

\section{Methods}

\section{Study site and site model}

The selected study area is the Lewis Creek channel and adjacent floodplain in the vicinity of the historic Quinlan Covered Bridge in Charlotte, northwestern Vermont (Fig. 2). The study reach is $1025 \mathrm{~m}$ long. The upstream drainage area of the river at this location is approximately $180 \mathrm{~km}^{2}$. The Lewis Creek watershed spans the Northern Green Mountain and Champlain Valley biogeophysical regions in northwestern Vermont. The region is characterized by a humid, temperate climate, with mean annual precipitation reported as $1074 \mathrm{~mm}$ (Olson 2014) and mean annual temperature recorded as $7.8{ }^{\circ} \mathrm{C}$ (NOAA 2016). Mean annual runoff ( $488 \mathrm{~mm})$ comprises $45 \%$ of the precipitation (USGS 2010), and surface waters drain to Lake Champlain. Land use in the Lewis Creek watershed is estimated as $62 \%$ forested, $26 \%$ agricultural and $8 \%$ developed (Troy et al. 2014).

Mean annual flows in the Lewis Creek are estimated as $3.1 \mathrm{~m}^{3} / \mathrm{s}$, based on historic records for a nearby US Geological Survey gaging station located nearly $6.5180 \mathrm{~km}$ downstream with a drainage area of $199180 \mathrm{~km}^{2}$. The peak flow recorded since 1990 is $133 \mathrm{~m}^{3} / \mathrm{s}$ on 27 April 2011 (USGS 2010). Regionally, the study reach of the Lewis Creek is located at the transition from a semiconfined valley to a much broader alluvial valley. In the 


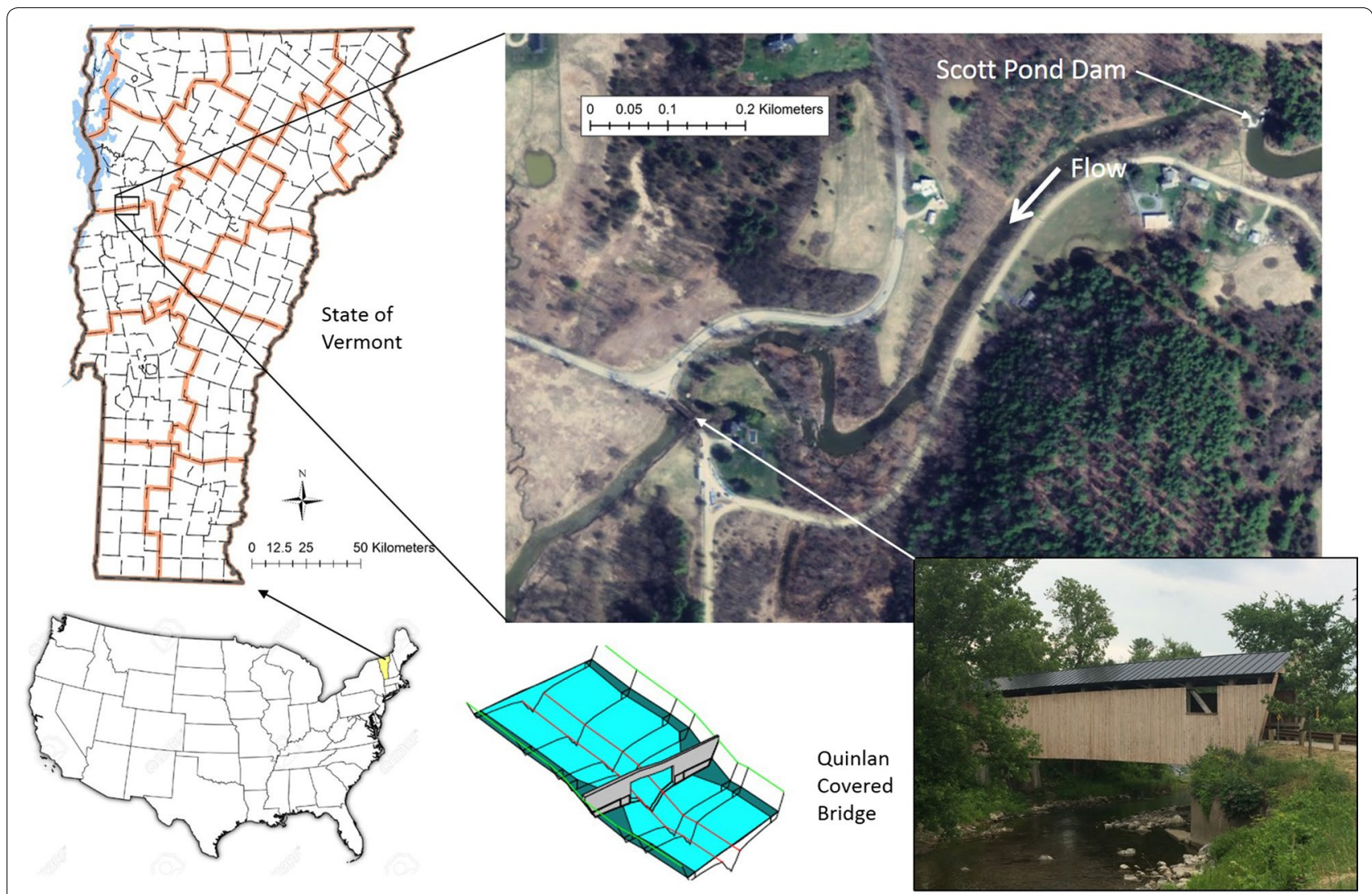

Fig. 2 Counter-clockwise from top-right: the location of the study site within Vermont; an aerial view of the modeled reach; and a picture of the bridge from the downstream side

upper half of the study reach the channel is constrained along the north bank by a moderate to steep, forested, valley wall and is vertically disconnected from the floodplain along the south bank which has been cleared and modified to accommodate a gravel road and light density residential development. In the lower half of the reach, the valley setting is more open and the degree of channel incision below the floodplain is less pronounced. Riparian areas are partly forested and partially in hay and lawn.

The Quinlan Bridge span (Fig. 3) is less than the natural bankfull width of the Lewis Creek channel, and the bridge is oriented at a sharp angle to the Lewis Creek. Flows are constricted through the bridge span leading to upstream aggradation and scour of the bridge abutments. Roads in vicinity of the bridge are elevated above the floodplain and both laterally and vertically constrain the channel and floodplain on approach to the bridge. Ice jams regularly cause localized flooding upstream and downstream of the bridge, threaten the integrity of the abutments of this historic bridge, and subject a nearby residential property to inundation and fluvial erosion hazards (SMRC 2010).
In 2010, an analysis of the bridge was contracted to provide recommendations on several alternatives to existing conditions for the purpose of reducing the risk of further damage. Mitigation scenarios considered included lowering adjacent roads, lowering the floodplain, removing berms and realigning the bridge (SMRC 2010). To perform the analysis, a HEC-RAS (Hydrologic Engineering Center-River Analysis System) model was built, calibrated and validated. HEC-RAS is a widely used river and stream modeling software (Goodell 2014) designed and distributed by the US Army Corps of Engineers (USACE.) It supports modeling of many hydraulic structures, including bridges, and simulations of alternatives provide the predicted physical variables needed (such as velocity and stage) to evaluate scour and erosive potential for proposed scenarios. HEC-RAS was used to evaluate and compare multiple scenarios related to encroachment as a proof of concept.

The reach modeled by Milone and Macbroom, Inc. is $1025 \mathrm{~m}$ long and drops approximately $5.8 \mathrm{~m}$ in elevation through the reach. The model extends from just upstream of the Scott Pond Dam (which operates in a 

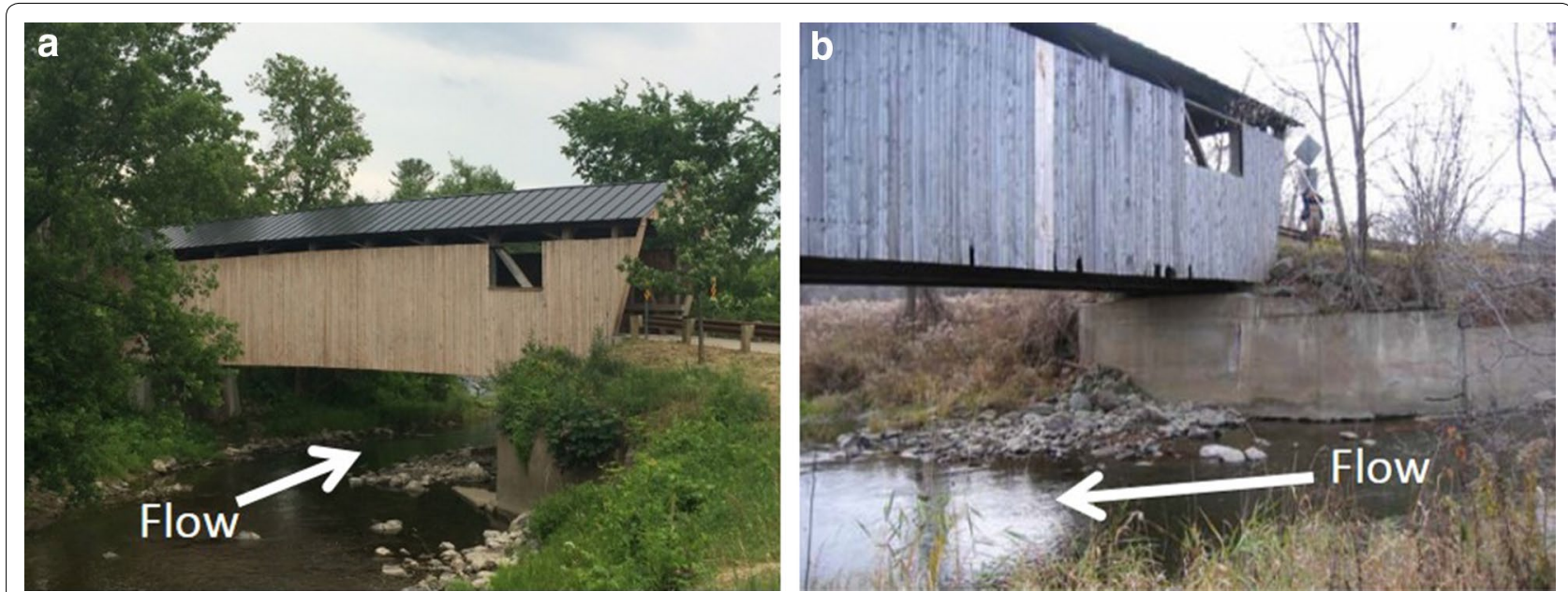

Fig. 3 The view of the bridge from upstream during a high-flow event (a) and cracking and undermining of the abutment of the bridge due to scour (b). Flow direction in both panels is indicated by arrows

run-of-river mode) to just downstream of the bridge, and is comprised of 13 cross sections. Eight of the 13 cross sections are labeled in Fig. 4. The model geometry shows the cross sections in plan view (Fig. 4a) as well as a cross section of the river along its length (Fig. 4b). Only these Eight cross sections include floodplain access modifications for the proof-of-concept presented in this work, as increasing floodplain access was not physically realistic at all locations. The cross sections are labeled with with $\mathrm{XS}_{1}$ representing the most upstream cross section and $\mathrm{XS}_{8}$ the most downstream. The bridge is between $\mathrm{XS}_{6}$ and $\mathrm{XS}_{7}$.

Flow magnitudes for various return periods were calculated by Milone and MacBroom using USGS streamflow gaging data from Lewis Creek, Station \#04282780 (USGS 2010), and regression equations (Olson 2002). Normal depth was used as a downstream boundary condition based on the original survey. The analysis of alternatives was primarily done using steady-state simulations, but a sediment transport analysis was performed to investigate the potential impact of erosion and sedimentation for the proposed alternatives. The latter requires a quasiunsteady analysis in HEC-RAS in which a transient event is modeled using a series of steady flows.

For steady flow simulations in HEC-RAS, stage and flow are calculated using energy losses between userdefined cross sections. For transient simulations, it solves the full 1-D St. Venant equations; HEC-RAS version 4.1, used for the Quinlan model, provides support only for 1-D modeling. The recently released version 5.0 provides support for 2-D flow modeling, however our data do not support 2-D simulations. In this work, transient simulations were used with an upstream hydrograph as a boundary condition. The hydrograph was constructed by scaling the quasi-unsteady hydrograph built by Milone and MacBroom for the sediment transport model so that peak flow corresponded with the design (50-year) flow. HEC-RAS routes this flow through the reach and provides hydraulic variables at the bridge for a given scenario.

\section{Scour prediction}

Models such as HEC-RAS provide the means to predict physical variables, such as flow, stage or velocity. These variables, in turn, can be used in empirical scour equations as described by the Federal Highway Administration (FWHA) in HEC-18 (Arneson et al. 2012).

Scour predictions were calculated in post-processing using the results of HEC-RAS simulations. The following contraction scour equation is selected for this work, and is one of many outlined by the FWHA in HEC-18 (Arneson et al. 2012):

$$
Y_{s}=4 Y_{0}\left(\frac{V_{0}}{\sqrt{g Y_{0}}}\right)^{\frac{1}{3}}(0.55) K_{1} K_{2},
$$

where $Y_{s}$ is the scour depth [m], $Y_{0}$ is the water elevation at the bridge $[\mathrm{m}], V_{0}$ is the flow velocity $[\mathrm{m} / \mathrm{s}], g$ gravitational acceleration $\left[\mathrm{m} / \mathrm{s}^{2}\right]$, and $K_{1}$ and $K_{2}$ are the skew and abutment coefficients, respectively.

Generally, the scour equations are overly conservative (Sheppard et al. 2014). However, for the purposes of evaluating bridge scour relative to a number of proposed scenarios, referred to here as relative scour risk, it is reasonable to interpret higher contraction scour values as corresponding to increased scour risk. While our results 


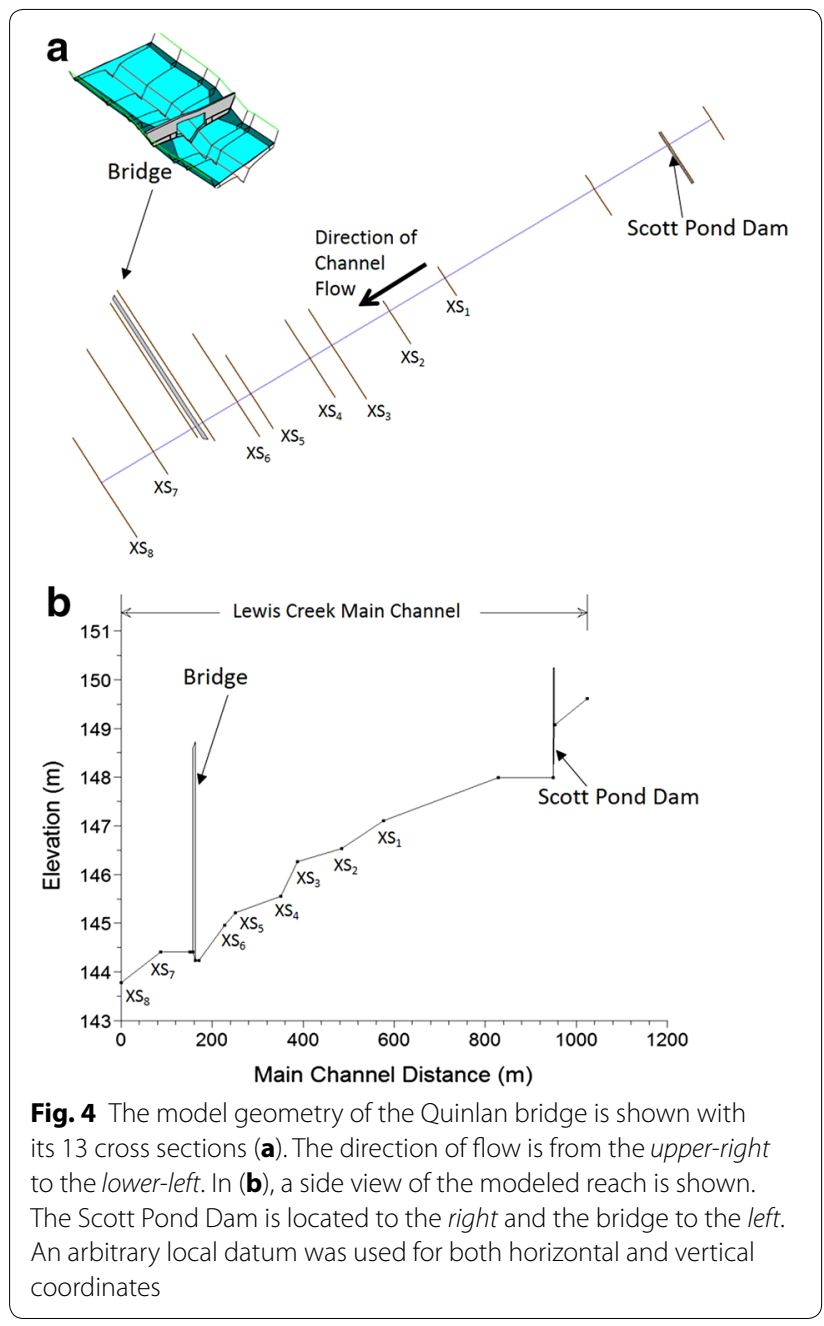

used the contraction scour equation, the methodology and the subsequent interpretation of the results would not change if a different scour equation was selected. As these equations are empirical, their validity is constrained to the range of data used to derive them.

When combined with the HEC-RAS model developed by Milone and MacBroom, Inc., Eq. (1) provides the needed hydraulic parameters, and enables scenarios to be evaluated and compared on the basis of bridge scour risk.

\section{Differential evolution (DE) optimization and HEC-RAS modifications}

This design challenge can be formulated as a multi-objective optimization problem. To demonstrate the application of a method for evaluating the location-dependent sensitivity of bridge scour to floodplain access and constriction, the Quinlan Bridge HEC-RAS model geometry was modified. The modified geometry represents this stretch of the Lewis Creek as having the maximum amount of floodplain access possible. The design flood was initially (and artificially) constricted entirely to the channel, thus providing no floodplain access up or downstream of the bridge. This is a noteworthy departure from current standard engineering methods and research, as the modified model does not reflect any proposed or hypothetical scenario. Optimization with DE was then used to find the most efficient removal of encroachments to minimize bridge scour at the Quinlan Bridge. To efficiently mitigate scour risk, different magnitudes of encroachment removal may be needed depending on the location; scour sensitivity to floodplain access can be inferred from these optimal encroachment removal values and locations ranked by their impact on scour. Locations that require more extensive encroachment removal to reduce scour are more salient.

Once the modifications to the HEC-RAS model were implemented, a DE optimization algorithm was wrapped around the model to impose floodplain constriction, enable HEC-RAS simulations, and post-process the calculated contraction scour results without using the graphical interface. Floodplain area was modified and HEC-RAS simulations then used to predict scour. Python code was written to provide this functionality using the HEC-RAS API [Application Program Interface (Goodell 2014)] and the ability to read and write to the HEC-RAS text files. In this work, the DE implementation in the Python library, SciPy, based on the description given by Storn and Price (1997), was wrapped around the combined HEC-RAS/cost function framework.

DE has several parameters that are user-defined. For this application, the crossover fraction was set to 0.7 and the mutation factor sampled from a uniform distribution in $(0.5,1)$ every generation. The population size was ten. Because DE is a stochastic method, optimization was repeated using random restarts to verify consistent convergence. For each of three values of the weighting parameter $\beta$ from Eq. (4), batch runs of ten random restarts were performed.

Removal of encroachments on both the left and right side of the channel (facing downstream) was defined along eight cross sections for a total of 16 variables. These variables are defined over a range from 0 to 1 , with 0 indicating no floodplain access (full constriction) and 1 indicating full floodplain access (no constriction). This is shown graphically in Fig. 5, with $\vec{x}$ being a vector whose components represent flood access corresponding to the left or right side of a particular cross section.

\section{Cost function}

Construction of the cost function is key, particularly when multiple objectives are involved or when constraints are being enforced using penalty terms, to ensure that solutions meet the constraints and specifications of 

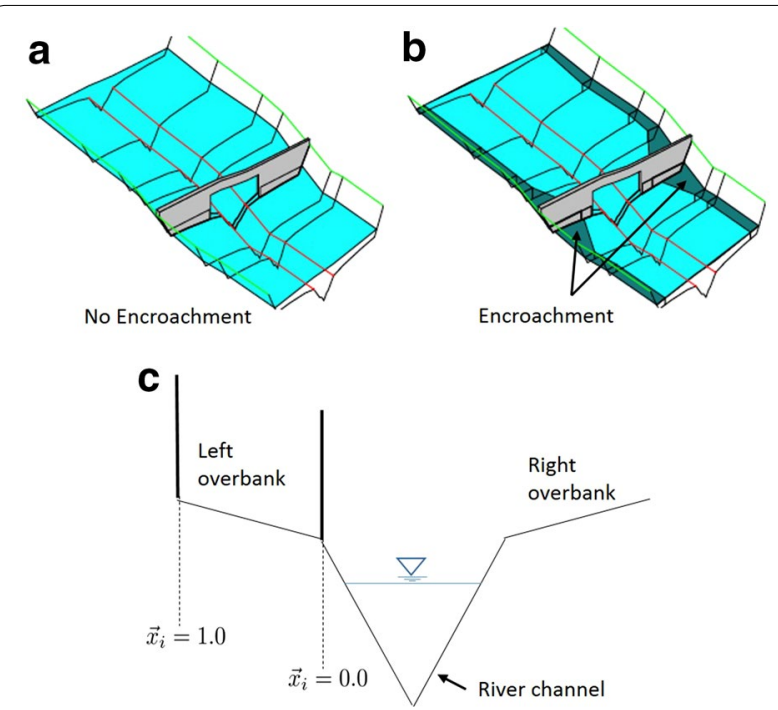

Fig. 5 HEC-RAS modeled bridge with no encroachments (a), with encroachments (b), and schematic showing removal of floodplain constrictions (c). For the location corresponding to the ith component of the decision vector, $\vec{x}_{i}=0$ specifies no relaxation of the constriction, i.e. no flow is permitted to access the floodplain. $\vec{x}_{i}=1$ specifies full floodplain access, ie. no encroachments

the real-world problem. A cost function was constructed to combine and weight the two competing objectives (floodplain access and bridge scour) into a scalar value as follows:

$$
\begin{aligned}
f(\text { floodplain access, scour })= & \text { floodplain access } \left.\text { sum }_{(2)}^{2}\right) \\
& +\left({\text { scour } \left.- \text { scour }_{\text {min }}\right)^{2} .}^{2}\right.
\end{aligned}
$$

with floodplain access a vector of unitless floodplain area values, scour the scour in meters, and scour $_{\text {min }}$ the userdefined threshold scour value. An optimal solution is one with low floodplain access (i.e. few built encroachments) and reduced bridge scour. These objectives are inversely correlated, so the trade-offs between them are defined by a set of pareto optimal (non-dominated) solutions. The cost function weights and combines these objectives into a scalar function to be minimized. Written with more succinct notation, Eq. (2) becomes:

$$
f\left(Y_{s}, \vec{x}\right)=\left(\sum_{i} \vec{x}_{i}\right)^{2}+\left(Y_{s}-Y_{s_{-} \text {min }}\right)^{2}
$$

The cost function is equal to the sum of the squares of the floodplain access parameters $\left(\vec{x}_{i}\right.$, where $i$ indexes location) and the amount of bridge scour $\left(Y_{s}\right)$ over baseline scour $\left(Y_{S_{\_} \min }\right)$ as determined by a simulation with fully open floodplains. It is a function of the entire set of floodplain access parameters encoded in $\vec{x}$ and the scour, which is an implicit function of $\vec{x}$, since the level of scour depends on the hydraulic behavior given a specified floodplain access scenario.

If the goal were to perform design optimization and identify a single floodplain design that maximizes encroachment along the eight selected channel locations while minimizing scour at the bridge, rather than evaluate sensitivity of individual locations along the channel, weighting parameters could be added to each term in Eq. (3) to define the trade-offs between the two stakeholder objectives. For the purposes of performing a sensitivity analysis, weights that determine the relative importance of objectives are not necessary because the optimal values of floodplain access will be evaluated relative to one another. In other words, they will be used to rank locations according to sensitivity and their absolute values will not be considered. To test this assumption, Eq. (3) was modified with a weighting factor, $\beta$, as follows:

$$
f\left(Y_{s}, \vec{x}\right)=\left(\sum_{i} \vec{x}_{i}\right)^{2}+\beta\left(Y_{s}-Y_{s_{-} \text {min }}\right)^{2} .
$$

Larger values of $\beta$ implicitly place greater weight on scour reduction, while values closer to zero weight minimization of floodplain access more heavily. Optimization was performed using values of $\beta$ that relatively weight the two objectives over two orders of magnitude.

\section{Results}

\section{Flood wave mitigation}

An initial exploratory investigation of system behavior was performed to guide future testing. The scour gradient was calculated using a one-sided finite difference approximation and defined as the rate of change of scour with respect to changes in floodplain access (Fig. 6). All sixteen components of the gradient are shown in terms of the physical locations they represent. Labels "XS 1", and letters " $L$ " and " $R$ " in a cross section for example, refer to the left and right overbanks, respectively, of the first cross section, $\mathrm{XS}_{1}$. The figure shows the approximate partial derivative of scour with respect to the corresponding component of $\vec{x}$. Figure 6 identifies only $\mathrm{XS}_{7}$, the location immediately downstream of the bridge, as having any noteworthy effect on bridge scour; all other locations have a negligible impact on simulated bridge scour.

To complement this finding, the up and downstream hydrographs for the 50 -year design storm for a simulation reflecting maximum floodplain access were plotted to assess the extent of flood wave attenuation and the role of naturally available floodplain access in the system. These hydrographs are shown in Fig. 7. There is no discernible difference between the up and downstream hydrographs, and therefore, no flood wave attenuation. This simulation 


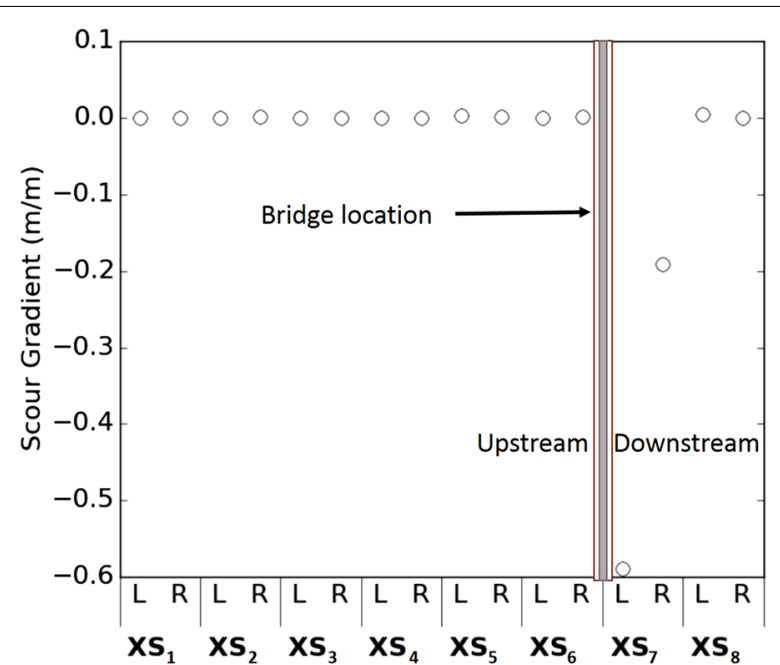

Fig. $\mathbf{6}$ The scour gradient, measured in meters of scour reduction per meter of encroachment removal, is shown for both the left and right overbanks for each of the eight cross sections. The most upstream cross section $\left(X_{1}\right)$ is at the far left and the most downstream $\left(X_{8}\right)$ at the far right

reflects the maximum amount of floodplain access, so no other plausible scenario would result in increased flood wave attenuation. The most likely explanation for this result is that the reach is simply not long enough and does not have sufficient storage volume in the floodplains. Scour potential is increased by increasing flow velocity and increasing water surface elevation. If upstream floodplain access does not attenuate flood waves, and there is

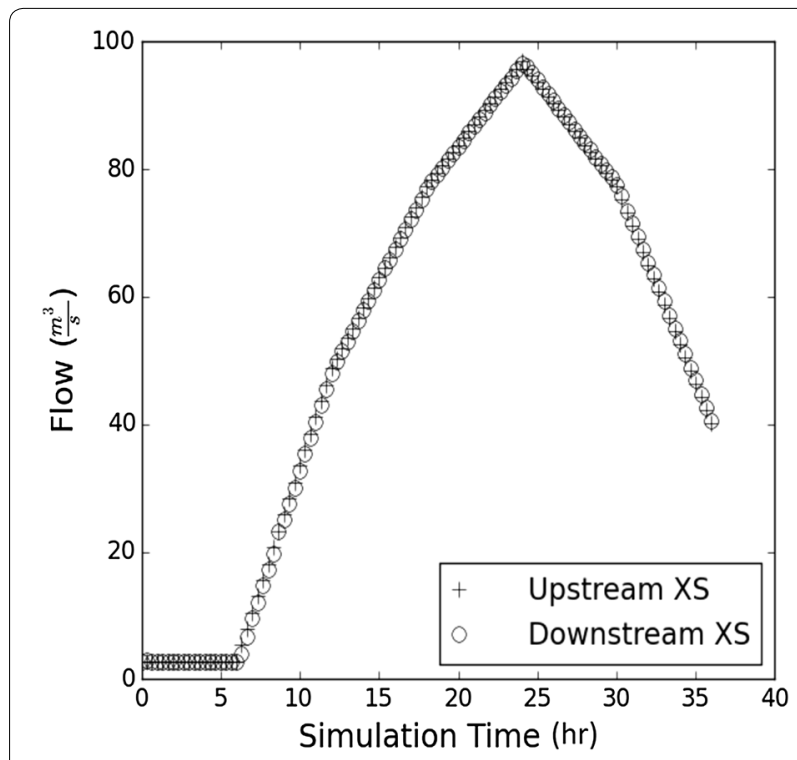

Fig. 7 Hydrographs at the most upstream and most downstream channel cross sections for a simulation performed with no floodplain constriction no corresponding decrease in flow velocity, then bridge scour for the design flood will be controlled by backwaters created by downstream constriction. When viewed together, the scour gradient and hydrograph data provide convincing justification for focusing only on the two variables corresponding to cross section $7\left(X_{7}^{R}\right.$ and $X_{7}^{L}$, the unitless encroachment parameters at the right and left side, respectively, of cross section 7) given the trivial impact that other locations have on bridge scour

\section{Global search results}

The optimal results generated by applying DE to three cost functions representing different weightings of objectives $(\beta=0.1, \beta=1$ and $\beta=10)$ are shown in Fig. 8 in coordinates normalized by the size of the floodplain. The results in unnormalized coordinates are shown in Fig. 9. For the purpose of sensitivity analysis, the ranking of two variables (i.e. the amount of left and right floodplain access at cross section 7) should be independent of weighting; all solutions should be on the same side of the line defined by $y=x$. Optimal solutions below and to the right of the $45^{\circ}$ line correspond to solutions where $X S_{7}^{R}<X S_{7}^{L}$. Solutions above and to the left of this line correspond to solutions where $X S_{7}^{R}>X S_{7}^{L}$. Optimal solutions for all three cost functions fall on the same side of the $y=x$ line and indicate the same sensitivity ranking of variables.

The results of all ten batch runs for all three cost functions are shown together in Fig. 8 to confirm consistent convergence of DE. DE performs its search for optimal solutions stochastically, so to increase confidence in the

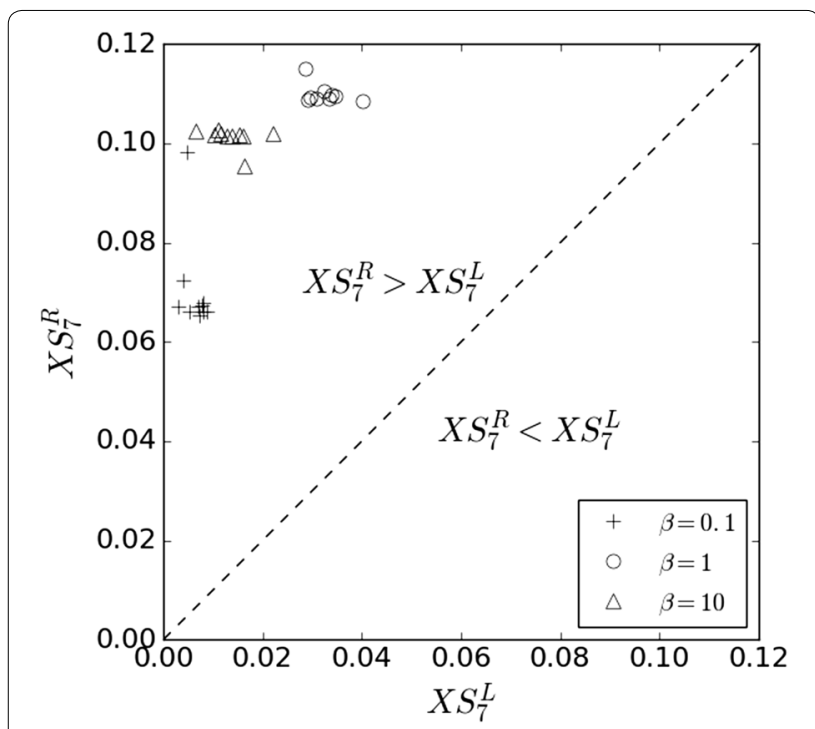

Fig. 8 Optimization results in the normalized coordinates for all three weightings of the two objectives 


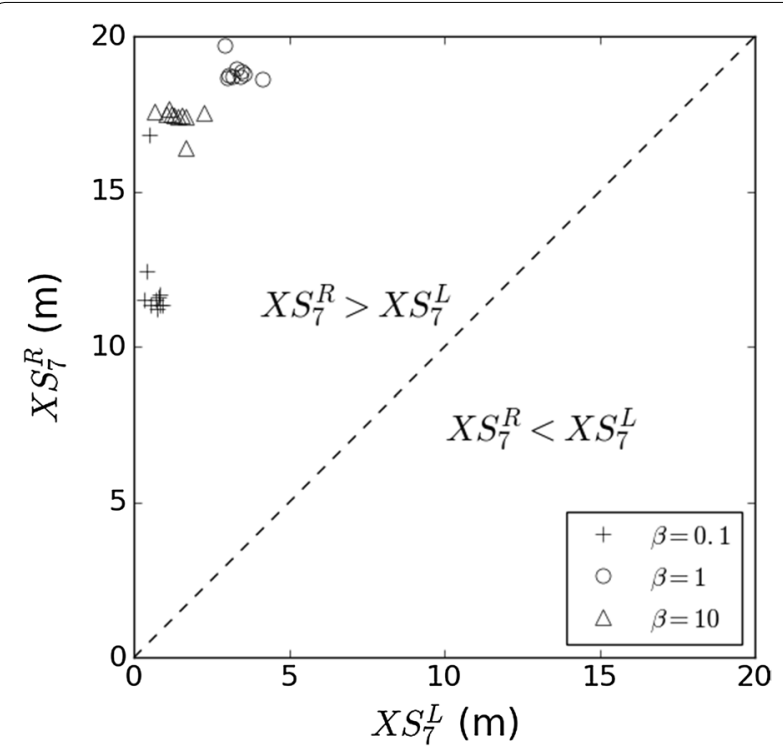

Fig. 9 Optimization results in the unnormalized coordinates for all three weightings of the two objectives

optimal results produced by DE random restarts were performed on all three cost functions. There is no way to ensure that the location it converges to is a true global optimum; thus random restarts (with different pseudo random number generator seeds) that converge to the same optimal solution increase the chances of finding a globally optimal solution or provide evidence that the initial results are not local sub-optimal solutions. For each cost function the results are clustered in the same region of the search space, indicating that convergence was consistent and representative of globally optimal solutions.

\section{Discussion}

The implemented methodology provides a framework for decision support in the form of a sensitivity analysis. Using optimization and a process-based model, the proposed methodology assesses the spatial variability of the impact of one objective on a system constraint. The system in this case is a river channel and the constraint of interest is contraction scour at a fixed bridge location. For demonstration purposes, optimization was performed using DE to minimize a cost function that increases with increasing bridge scour (the constraint) and increasing floodplain access (the spatially-dependent design variable.) The desired outcome is a ranking of floodplain access by location in terms of impact on bridge scour under a defined design flow (i.e., flood of 50-year return interval). We interpret the optimal connected floodplain at a specific cross section of a river as an indicator of the relative impact of floodplain access at that location to bridge scour.
Optimization performed on this system results in a set of spatially dependent optimal floodplain access values as the connected floodplain shape (plan view width) is changed to optimize the objective function. The proposed method is distinct from the design optimization process, instead leveraging numerical optimization and a constructed cost function to evaluate the relative spatial sensitivity of one objective with respect to another. Although it is straightforward to rank locations according to their respective optimal values, the interpretation of this information as relative sensitivity is not. The optimization process performed in this work provides evidence that this is a reasonable interpretation.

The scour gradient was earlier defined as the rate of change of scour with respect to changes in floodplain access at specific locations along the channel. The gradient at maximum constriction can be easily interpreted as relative sensitivity by noting that locations where the scour is reduced more per unit of increased floodplain access have a greater impact on bridge scour. These results suggest that bridge scour at the Quinlan Bridge system is controlled primarily by a backwater created by downstream constrictions. This implies that upstream reach storage effects at this particular site do not significantly mitigate the design flood wave. The up and downstream hydrographs at maximum floodplain accessibility confirmed this interpretation, showing very little flood wave mitigation between the top and bottom of the reach (Fig. 7). The gradient results (Fig. 6) also indicate that only the cross section immediately downstream of the bridge had any noteworthy effect on bridge scour, and that scour was more sensitive to floodplain access on one side of that cross section than the other. The finding that only downstream floodplain constriction causing backwater has an impact on bridge scour is specific to floodplain access and is a result of insufficient upstream storage area in the floodplains. The channel is vertically disconnected from much of the study reach at the stage of the 2-year flood-significantly lower than the 50-year design storm used for performing the sensitivity analysis. This may partially explain the lack of floodplain storage (and resultant negligible flood wave attenuation).

Optimization of the cost function was consistent for all three cost functions (values of weighting parameter $\beta$ ) with identical rankings of the two salient decision variables. Optimization resulting in identical ranking of variables for all three values of $\beta$ indicates that the sensitivity analysis is roughly independent of the weighting of the objective terms in the cost function. A result of this finding is that the method does not rely on a precise weighting of objectives by stakeholders-the sensitivity analysis is identical across objective weights. While the site in question does not have upstream sensitivity, in a reach with more salient locations 
(i.e. more locations where floodplain access impacts bridge scour) the method could be applied analogously to rank more than the two locations ranked in this work.

The reliability of the underlying model itself is important when assessing the reliability of the sensitivity analysis. In this work energy losses and erosive effects, due to sharp changes in direction of the stream channel, cannot be modeled using the 1-D St. Venant equations solved in HEC-RAS 4.1. In their report, Milone and MacBroom noted the sharp turn in the stream immediately preceding the bridge. One of the bridge scour mitigation measures briefly considered was to realign the stream and straighten its approach to the bridge. However, from a stream geomorphic perspective it was judged to be both prohibitively expensive and ultimately ineffective.

However, this sharp turn in the stream channel must be considered in terms of its impact on the sensitivity results. A picture of the sharp approach is shown in Fig. 3a. Without a more detailed representation of the site physics (e.g. a 2-D model), it is difficult to determine the extent to which the 1-D HEC-RAS modeling approach oversimplifies the bridge scour and erosion dynamics. Two dimensional modeling, like that now available in HEC-RAS 5.0, would be a logical next step to confirm the sensitivity findings of this work, and to evaluate the site itself as a candidate for further study using 2-D models. However, even without this 2-D analysis there are good reasons to trust the results. The backwater-controlled scour is dependent on lack of floodplain storage volume, a detail that is not affected by not modeling potential 2-D energy loss effects. Thus, the conclusion implied by the sensitivity analysis that downstream floodplain access is more salient to bridge scour mitigation than access upstream is a direct result of this finding, and it is therefore likely that substituting a 2-D model would not substantively change the sensitivity analysis. Even if there are noteworthy erosive effects not captured in the 1-D model, these would be more relevant to accurate and quantitative prediction of bridge scour at the site than the sensitivity analysis presented in this work.

In general, the proposed methodology is independent of either model or optimization technique. It requires that there be an objective of interest (in this case floodplain access) that impacts another objective or constraint (in this case bridge scour). A model, capable of simulating different scenarios and calculating these objective(s) and constraint(s), must exist. If the competing objectives are functions of space, then a ranking with this method may be performed, provided the model is not too computationally expensive for the chosen optimization algorithm. The latter was not the case for this application. If the model were more computationally expensive or the search space much larger, an alternative optimization algorithm may be warranted. However, this does not materially impact the interpretation proposed in this work, and the relative ease of the optimization makes it unlikely that different algorithms would produce different results.

\section{Conclusions}

This work presents a new approach to applying DE optimization to engineering challenges, and tests that approach on a real site. The technique involves constructing a cost function in such a way that the multi-objective "optimal" results do not represent an optimal design in the traditional sense of minimizing a collective set of two or more constraints, but rather represent the sensitivity of a given constraint or objective of interest with respect to a second objective or constraint-a novel interpretation of optimization results. Because optimal decision variable values are assessed relative to one another and do not represent a specific design or reflect stakeholderdefined preferences of objectives, the need to specify the relative importance of objectives is relaxed. The constraint used to demonstrate the approach was bridge scour with respect to floodplain access, and the system was a river system comprising natural channel geometry and built structures (a bridge). The use of DE on constructed cost functions representing different weightings of the two objectives provided the same rank-order of reach locations with respect to their floodplain access impact on predicted bridge scour; ancillary testing using a finite difference scour gradient supports the proposed interpretation. Also of interest is that the sensitivity analysis is somewhat independent of objective weighting, which potentially reduces the stakeholder burden of deciding how to weight competing objectives. Instead, this approach focuses analysis on elements of the system's behavior that can be used to guide the design of floodplain infrastructure, remediation efforts, or the placement of new bridges. Applying this approach to other rivers would focus attention on locations where increased floodplain access would result in the most efficient use of resources, and applying it to other systems with spatiallyvariable components which have functional relationships with objectives of interest to stakeholders may provide similar decision support information.

\footnotetext{
Authors' contributions

LH made significant contributions in conceptual design and writing, and performed the majority of the coding and data analysis. IA contributed to the development of study design from the early stages, worked on the figures, and wrote or edited sections related to DE. KU provided her expertise on the study site, the model, and the interpretation the real-world implications of the results; she wrote sections of the manuscript related to the specifics of the site and model. MD provided expertise on bridge scour, ensuring that applicationspecific best-practices were employed, as well as reviewed and edited the manuscript at various stages. LD provided expertise on optimization techniques and applications, reviewed and provided input on the optimization
} 
portions of study design throughout the project, and reviewed and provided input on the manuscript. DR was closely involved at all stages of the project, making contributions to study design, interpretation of results, production of figures and the manuscript itself through multiple rounds of editing and review. All authors read and approved the final manuscript.

\section{Author details}

'Civil and Environmental Engineering, University of Vermont, 33 Colchester Avenue, Burlington, VT 05405, USA. ${ }^{2}$ Hydrogeologic, Inc., 11107 Sunset Hills Road \#400, Reston, VA 20190, USA.

\section{Acknowledgements}

This work was partially supported by the Vermont Agency of Transportation (VAOT), the United States Department of Transportation through the University of Vermont Transportation Research Center, and Vermont EPSCoR with funds from the National Science Foundation Grant EPS-1101317. The views and findings stated here are those of the authors, and do not reflect the views and findings of the Agencies mentioned. The authors are grateful to Milone \& MacBroom, Inc. for providing their HEC-RAS model, Prof. Margaret J. Eppstein for inspiring the use of differential evolution within the context of bridge scour, and for the generous support provided by Hydrogeologic, Inc

\section{Competing interests}

The authors declare that they have no competing interests.

Received: 12 April 2016 Accepted: 9 August 2016

Published online: 30 August 2016

\section{References}

Anderson IA, Dewoolkar MM, Rizzo DM, Huston DR (2014) Scour related Vermont bridge damage from tropical storm irene. In: Structures congress, pp 505-515

Arneson L, Zevenbergen L, Lagasse P, Clopper P (2012) Evaluating scour at bridges. Tech. rep, National Highway Institute

Bartholomew-Biggs M, Parkhurst S, Wilson S (2002) Using direct to solve an aircraft routing problem. Comput Optim Appl 21:311-323

Briaud JL, Gardoni P, Yao C (2014) Statistical, risk, and reliability analysis of bridge scour. J Geotech Geoenvironmental Eng 140(2). doi:10.1061/ (ASCE)GT.1943-5606.0000989

Deschaine LM, Lillys TP, Pinter JD (2013) Groundwater remediation design using physics-based flow, transport and optimizatioin technologies. Environ Syst Res 2(1):1

Dougherty DE, Marryott RA (1991) Optimal groundwater management: 1. simulated annealing. Water Resour Res 27(10):2493-2508

Fowler K, Jenkins E, Ostrove C, Chrispell J, Farthing M, Parno M (2015) A decision making framework with modflow-fmp2 via optimization: determining trade-offs in crop selection. Environ Model Softw 69:280-291

Goodell C (2014) Breaking the HEC-RAS code: a user's guide to automating HEC-RAS. h2ls

Guerra-Gómez I, Tlelo-Cuautle E, de la Fraga LG (2013) Richardson extrapolation-based sensitivity analysis in the multi-objective optimization of analog circuits. Appl Math Comput 222:167-176

Harsha Choday S, Roy K (2013) Sensitivity analysis and optimization of thin-film thermoelectric coolers. J Appl Phys 113(21):214906

Hornby GS, Lohn JD, Linden DS (2011) Computer-automated evolution of an $x$-band antenna for Nasa's space technology 5 mission. Evolut Comput 19(1):1-23

Jaffe DA, Sanders BF (2001) Engineered levee breaches for flood mitigation. J Hydraul Eng 127(6):471-479. doi:10.1061/ (ASCE)0733-9429(2001)127:6(471)

Jeongwoo H, Papalambros PY (2010) Optimal design of hybrid electric fuel cell vehicles under uncertainity and enterprise conditions. J Fuel Cell Sci Technol 7(2):021020

Katell J, Eriksson M (1998) Bridge scour evaluation: screening, analysis, \& countermeasures. Tech. Rep. 98771207, STCDC, San Dimas, CA

Kouchakzadeh S, Townsend R (1997) Maximum scour depth at bridge abutments terminating in the floodplain zone. Can J Civil Eng 24(1):996-1006
Kurek W, Ostfeld A (2013) Multi-objective optimization of water quality, pumps operation, and storage sizing of water distribution systems. J Environ Manag 115:189-197

Li FF, Schoemaker CA, Qiu J, Wei JH (2015) Hierarchical multi-reservoir optimization modeling for real-world complexity with application to the three gorges system. Environ Model Softw 69:319-329

Liou CD, Wang KH, Liou MW (2013) Genetic algorithm to the machine repair problem with two removable servers operating under the triadic $(0, q, n$, m) policy. Appl Math Model 37(18-19):8419-8430

Luke A, Kaplan B, Neal J, Lant J, Sanders B, Bates P, Alsdorf D (2015) Hydraulic modeling of the 2011 new Madrid floodway activation: a case study on floodway activation controls. Nat Hazards 77(3):1863-1887

Marsden AL, Wang M, Dnnis JE Jr, Moin P (2004) Optimal aeroacoustic shape design using the surrogate management framework. Optim Eng 5:235-262

Melville BW, Coleman SE (1973) Bridge scour. Water Resources Publications, LLC, Littleton

Mesfin G, Shuhaimi M (2010) A chance constrained approach for a gas processing plant with uncertain feed conditions. Comput Chem Eng 34(8):1256-1267

Mugunthan P, Shoemaker CA, Regis RG (2005) Comparison of function approximation, heuristic, and derivative-based methods for automatic calibration of computationally expensive groundwater bioremediation models. Water Resour Res 41(11):n/a-n/a, w11427

NOAA (2016) Mean annual temperatures at Burlington Vermont international airport: 2000-2015. http://w2.weather.gov/climate/xmacis.php?wfo=btv

Olson SA (2002) Flow-frequency characteristics of Vermont streams. WaterResources investigations report 02-4238, USGS

Olson S (2014) Estimation of flood discharges at selected annual exceedance probabilities for unregulated, rural streams in Vermont, with a section on vermont regional skew regression, by veilleux, a.g. Scientific Investigations Report 5078, US Geologic Survey

Pugh C (1985) Hydraulic model studies of fuse-plug embankments. Tech. rep., Hydraulics Branch, Division of Research and Laboratory Services, Engineering and Research Center, US Dept. of the Interior, Bureau of Reclamation, Denver, CO

Rios LM, Sahinidis NV (2012) Derivative-free optimization: a review of algorithms and comparison of software implementations. J Global Optim 56(3):1247-1293

South Mountain Research and Consulting, Milone \& MacBroom Inc (2010) Quinlan bridge area alternatives analysis to reduce flood and erosion risks. Tech. rep, Lewis Creek Association

Rizzo DM, Dougherty DE (1996) Design optimization for multiple management period groundwater remediation. Water Resour Res 32(8):2549-2561

Schmocker L, Höck E, Mayor PA, Weitbrecht V (2013) Hydraulic model study of the fuse plug spillway at Hagneck canal, Switzerland. J Hydraul Eng 139(8):894-904. doi:10.1061/(ASCE)HY.1943-7900.0000733

Sheppard D, Melville B, Demir H (2014) Evaluation of existing equations for local scour at bridge piers. J Hydraul Eng 140(1):14-23

Shlomi S, Ostfeld A, Rubin H, Shoemaker C (2010) Optimal groundwater contamination monitoring using pumping wells. Water Sci Technol 62(3):556-569

Storn R, Price K (1997) Differential evolution-a simple and efficient heuristic for global optimization over continuous spaces. J Global Optim 11:341-359

Troy A, Wang D, Capen D, O'Neil-DUnne J, MacFaden S (2014) Updating the lake champlain basin land use data to improve prediction of phosphorus loading. Tech. Rep. 54, University of Vermont, Lake Champlain Basin Program

USGS (2010) National water information system. Web interface

Vesterstrom J, Thomsen R (2004) A comparative study of differential evolution, particle swarm optimization, and evolutionary algorithms on numerical benchmark problems. In: Evolutionary computation, 2004. CEC2004. Congress on, vol 2, pp 1980-1987

Wardhana K, Hadipriono FC (2003) Analysis of recent bridge failures in the United States. J Perform Constr Facil 17(3):144-150. doi:10.1061/ (ASCE)0887-3828(2003)17:3(144)

Xu Z, Lu S (2011) Multi-objective optimization of sensor array using genetic algorithm. Sens Actuators B Chem 160(1):278-286 